\title{
Influence and Strategies of Economic Crisis on China's Livestock Farming
}

\author{
${ }^{1}$ Jian-Ying Wang, ${ }^{1,2}$ Zou-Ran Lan, ${ }^{2}$ Fu-Lin Tian and ${ }^{1}$ Xiu-Mei Zhang \\ ${ }^{1}$ Shandong Provincial Key Laboratory of Animal Disease Control and Breeding, \\ Institute of Animal Science and Veterinary Medicine, \\ Shandong Academy of Agricultural Sciences, 250100 Ji'nan, P.R. China \\ ${ }^{2}$ Shandong Provincial Animal Disease Prevention and Control Center, 250022 Ji'nan, P.R. China
}

\begin{abstract}
Livestock farming is crucial for the development of agriculture. Understanding the impact of the financial crisis to China's animal husbandry and positively responding to it are very important to ensure the stable, sustainable development of animal husbandry. This study describes where the influence of economic crisis on livestock farming is in China and gives strategies we should take in detail that is the government should continue assisting, speed up the reform of veterinary management system and stabilize rural veterinary number, adjust and optimize the industrial layout, change the production system, strengthen the popularization and application of science and technology, establish and perfect information platform of animal husbandry, develop and cultivate market at home and abroad form cooperatives and stand up against the cold wave together. Those strategies will give important lessons to the other developing countries.
\end{abstract}

$\underline{\text { Key words: Economic crisis, livestock farming, influence, husbandry, China }}$

\section{INTRODUCTION}

As the pillar industry of agriculture, the rise and fall of animal husbandry are directly related to the peasants' income. The influence of economic crisis to current Chinese economy is gradually deepened and animal husbandry is no exception but not as much as the other industries. Understanding the impact of the financial crisis to China's animal husbandry and positively responding to the crisis are very important to ensure the stable, sustainable development of animal husbandry, the adjustment of agricultural production structure and the healthy development of food processing industry, animal machine tool manufacturing and biological medicine etc.

The economic impact to animal husbandry is in the following aspects: firstly, increasing returned peasant laborers will make full use of the preferential policies of animal husbandry, the bosses of inefficient industry and mining enterprises will turn over to animal husbandry which could lead to the increase of small-scale raising households and scatter-feed households and affect the developing process of intensive animal husbandry; secondly, the decline of the people's consumption purchasing power will lead to a weak market and the prices of livestock products are coming down; thirdly, rising prices of raw materials, energy and building materials have greatly increased the production costs of the livestock breeding industry which dampen the workers' enthusiasm of production; fourth, the aftereffect of animal husbandry development was handicapped by the strict control of animal husbandry using land, financing difficulty, export difficulty and risky.

Economic crises have brought not only impacts on but also challenges to animal husbandry. To meet challenges and seize new opportunities, researchers must make effective plans and measures.

Plane 1: The government should continue assisting.

In the recent years, the state council has issued a series of policies to assist the development of animal husbandry which have increased the investment and guaranteed its healthy development (Wang, 2009a). The local governments should contact with the relevant department and make full use of the National Financial Supporting Policy, Tax Preferential Policy, Conversion on Cropland to Forests Policy, Assisting the poor Policy, Rural Jot Credit Loan Policy, the New Rural Communities Construction Policy and the other local policies to develop agriculture and help farmers, make the output value of animal husbandry to occupy half of that of agriculture.

Optimizing the investment environment, giving the greatest convenience and tangible benefits in terms of administrative examination and approval, administrative execution and administrative management.

Corresponding Author: Xiu-Mei Zhang, Shandong Provincial Key Laboratory of Animal Disease Control and Breeding, Institute of Animal Science and Veterinary Medicine, Shandong Academy of Agricultural Sciences, \#10 Sangyuan Rd, 250100 Ji'nan, P.R. China 
Giving the preferred financial support position to the scientific research in animal husbandry, improving the proportion of science and technology of animal husbandry and the agriculture to that of the national.

Strengthening the public infrastructure construction of livestock industrialization raising community, water circuits and the application of frozen semen.

Guiding and encouraging loans to animal husbandry from different financial institutions for its financial support.

The government should further increase investment, formulate practical female protection policies and timely introduced the lowest offer of animal by-products, encourage and protect the raising initiative of farmers.

The government and the associations should provide information advisory services for enterprises, standardize breeding farm, intensify its supervision and regulation, suitably reduce the number of intermediate links and ensure the interests of producers.

Replacing compensation by reward, encouraging healthy breeding style, giving special support to innocuous treatment of livestock and poultry manure and the implementation of biogas in order to improve the residential environment.

The national livestock insurance mainly covering the natural hazards in animal husbandry, farmers still confronting with two major risks-market and plague, agricultural insurance is essential to be legislated, give necessary financial support to the insured enterprises and individuals for the economic development of animal husbandry.

Plane 2: Speed up the reform of veterinary management system, stabilize rural veterinary number (Zhou and Jiang 2006).

Grasp the opportunities that building the new socialist countryside in China, strengthen the infrastructure facilities construction of animal epidemic disease, especially avian influenza, improve and perfect emergency response system on important animal epidemic.

Perfect quality and safety law of animal products, strengthen the supervise efforts on feed, veterinary medicines and animal product operation. Establish credibility files for individual breeding farm, prevent selling or using illegal drugs and additive during the production, processing and circulation, completely eradicate the marketing of dead livestock and poultry, ensure the security of animal products and the sustainable development of animal husbandry from the source.

Crisis events which have affected the health quality of animal products should be investigated and treated in accordance with relevant regulations of the country and local governments, persons concerned should be given severe punishment.

Strengthen the construction of animal epidemic prevention facilities in basic unit, ensure wages and benefits of the veterinarian staffs at the grass-roots level and stabilize the number of veterinarian at the primary level. Local veterinarian must hold relevant certificates, epidemic prevention, quarantine inspection and supervision work should be conducted effectively.

Apart from vaccine procurement funds, animal epidemic monitoring funds should be included in fiscal budget at different levels. Work funds and subsidies for loss of working time should also be guaranteed. Breeding farmers whose mass animals have been preyed on for preventing the spread of infectious diseases such as avian influenza should be given direct subsidies according to the costs to reduce losses.

Plane 3: Adjust and optimize the industrial layout and change the production system.

Adjust the industrial structure of animal husbandry according to market and resources; centralize the industrial layout on advantageous regions. Intensified and large-scale dairy cow, pig and chicken breeding should be steady developed and special economic animal breeding should be supported and encouraged at suburbs; dairy cattle, fattening cattle and sheep should be given priority to the agricultural region of China, conversion and utilization of food and crop straws should be promoted as well.

To connect a complete chain of leader enterprises, farms and economic cooperation organization of animal husbandry should make production, supplies, processing and marketing a coordinated process. Breeding districts model can be introduced if possible or according to the industrialization development model such as company plus farm plus households, association plus households, implement standardized production, improve epidemic prevention conditions, unify breeding, feed, veterinary medicine and epidemic prevention, improve mechanization levels of raising, popularize advanced production equipment, guarantee product quality and strengthen the protection of industries against risks (Zhou and Jiang 2006).

The transformation of production mode should stress the following (Wang, 2009b): along with the improving of the living standard, the demand for mutton and beef is expected to grow by $15-20 \%$. Beef cattle, dairy cattle and meat sheep industry should strive to develop in order to grasp the opportunity that the prices of sheep and cattle products is continuing to go higher and the market is promising; fully exploit the digestibility of green fodder, 
develop and utilize green fodder resources, analyze the reliable way to improve conversion rate of green fodder and yield balanced nutrition forage formula of concentrated feed to reduce forage costs and alleviate the human-animal fighting for grain as food; actively explore the implementation of ecological breeding and circulated cropping-breeding coupled mode, develop and construct green energy, improve the rural ecological environment, control and manage the waste and pollution by breeding to the utmost and strive to make waste profitable.

Plane 4: Strengthen the popularization and application of science and technology.

Perfect the system of animal husbandry and veterinary services, enhance the science and technology content of breeding, improve the enthusiasm of breeding farmers in standardized and large-scale breeding and lead them to standardized operation.

Human resources development should be given top priority to. Introduce persons of outstanding ability to knowledge and management coordination; on the other hand, create a platform that employees can utilize their ability and wisdom as much as they like. To keep up with the times, we should learn to study and improve the management level and professional skills and exploit new growth point of profit.

Popularize basic epidemic prevention knowledge and promote healthy breeding mode. According to the requirement of the socialism new rural reconstruction regarding the village accommodates neat, actively guide and help farmers to solve the housing mix problems of human and livestock, improve rural living conditions, control the pollution of pathogenic microorganism, devote great efforts to the prevention of infectious disease suffered by human being (Zhou and Jiang, 2006).

Speed up the construction of livestock and poultry breeding, increase allowance and protect genetic resources for restore production and sustainable development (Zhou and Jiang, 2006). Adjust livestock population structure and breeding scale, introduce new breed, eliminate those population old or with low production performance. Improvement should be done wherever possible, strengthen molecular biology and genetic engineering research, excavate and exploit useful high yield or disease-resistance genes, choose related molecular markers and pursue self-renovation way.

Popularize and apply forage processing technology, frozen semen technology, storage technology of straw forage and biogas technology, etc. Reduce production costs, increase peasant incomes and improve the standardized, scale and professional level of animal breeding.
Unify production, study and research, carry out various forms of technical cooperation and timely introduce new achievements and new technologies of animal husbandry with the aid of the basic research advantages of high schools and research institutes.

Strengthen the efforts in publicity, arm peasants with modern animal husbandry knowledge and improve their theory and technique level. Various forms can be adopted: set up expert consulting service on breeding technology, ask experienced experts to give concentrated lessons, learn from the excellent breeding farm; regularly exchange experience with other farmers to make full use of favorable condition and promote complementarities.

Plane 5: Establish and perfect information platform of animal husbandry.

Information system construction of animal husbandry should be paid attention to by animal husbandry department at all levels. More should also be done, perfect epidemic report network, immune and epidemic surveillance network, increase immune density, ensure immunization effects and guarantee the production safety of animal products from the source. Build supply and marketing information platform of animal products which farmer can share information quickly and communicate with each other, service as a bridge for enterprises to help them out. It is essential for the farmers to grasp the information regarding price fluctuations, supply-demand relationship and animal feed price etc., seize opportunities, act according to circumstances and learn how to solve the difficulties (Tao, 2009).

Plane 6: Develop and cultivate market at home and abroad.

To avoid the economic impact on animal husbandry, researchers should fully exploit the rural consumption market. The government can expand domestic demand through publicity and granting consumption coupons to avoid the losses. New protein feed resource should be opened up to reduce production costs and marketing strategy should be innovated, sales model can be door to door, chain supermarkets and online marketing, etc.

Brands building should be promoted and lowtemperature and cooked meat products should be developed. Provided that the existing market is stabilized, the corporations should exert themselves to promote the competitive power in the international market and open new livestock product export markets through the authentication of pollution-free, green or organic foods, expanding awareness and establishing their own special brands. 
Plane 7: Enhance confidence, form cooperatives and stand up against the cold wave together.

\section{CONCLUSION}

Facing the complex situation, the livestock farmers should establish relationships with a horizontal or parallel department or area to cooperate mutually, form breeding industry, share interests and risks together, integrate production and marketing with leading enterprise for industrial management. On the other hand, we should strengthen the confidence, improve the skills, raise the quality of livestock products, increase economic efficiency and strengthen risk resistance capacity. Researchers should also realize that livestock products are sold mainly on the domestic market, their economic impact from financial crisis are relatively small, the development of the breeding industry is being supported in all possible ways via policies and project funds from governments, the market demand of livestock products is growing and the breeding benefits will remain to be good over a long period of time (Wang, 2009b).

\section{ACKNOWLEDGEMENTS}

This research was supported by the Special Fund for Agro-scientific Research in the Public Interest (200903014-06); the Postdoctoral Innovation Funds of Shandong Province (200803017) and the Distinguish Young Scientists Foundation of Shandong Province (2008-BS0-2016).

\section{REFERENCES}

Tao, D.Z., 2009. Crisis and coping mechanism in animal husbandry. Hubei Anim. Husbandry Veterinary Med., 1: 8-10.

Wang, Y.T., 2009a. The development of animal husbandry in China under the financial crisis. Mod. Bus. Trade Ind. J., 11: 14-15.

Wang, Y.Q., 2009b. Ponders on animal husbandry development under financial crisis. Pig Ind. Economy J., 6: 25-26.

Zhou, W. and H.F. Jiang, 2006. Raising the crisis management level of animal husbandry in China. Guide Chin. Poul. J., 23: 15-17. 